\title{
Sustaining the Development Goals in Drug Approaches in Europe, Norway and Singapore
}

\author{
Rathna N. Koman \\ School of Law, Singapore Management University, Singapore City, Singapore \\ Email: rathnakoman@smu.edu.sg
}

How to cite this paper: Koman, R. N. (2019). Sustaining the Development Goals in Drug Approaches in Europe, Norway and Singapore. Beijing Law Review, 10, 882-912. https://doi.org/10.4236/blr.2019.104048

Received: July 15, 2019

Accepted: August 29, 2019

Published: September 2, 2019

Copyright $\odot 2019$ by author(s) and Scientific Research Publishing Inc. This work is licensed under the Creative Commons Attribution International License (CC BY 4.0).

http://creativecommons.org/licenses/by/4.0/

\begin{abstract}
This article aims to establish that national drug approaches in Europe, Norway and Singapore though different are aligned in accordance with the sustainable development goals articulated by the Global Commission on Drug Policies in 2015. The Commission listed 17 developmental goals reflecting the different dimensions of the five sustainable developments: 1) social development; 2) economic development; 3) environmental sustainability; 4) peaceful, just and inclusive society; and 5) global partnerships. This paper primarily aims to argue that though the harm reduction drug approach in the classic binary categorization of drug approaches reflects adherence to the sustainable development goals, drug approaches in Norway and Singapore are not contrary to sustainable development. A contextual and comparative analysis of the approaches in Europe, Norway and Singapore is offered to demonstrate that eradication drug policies coupled with increasing and strong harm reduction fundamentals such as rehabilitation, science and evidence based treatment interventions, reintegration of drug inmates into society, are consistent with the Commission's sustainable developmental goals. The paper anchors upon this comparative analysis of the harm reduction services available in these approaches to demonstrate the fine balance struck between prohibitionists and harm reduction fundamentals within each national drug approach to achieve alignment with sustainable development goals. Two other ancillaries pertinent to sustainable drug approaches are also considered: health outcomes/indicators and delinking drug policy from abstinence. It is recommended that health and development indicators be used in metrics to judge success of drug approaches, given its impact on the five dimensions of sustainable development. Last, the Commission's approach to sustainable development signals a fundamental change in mindset to drug use, control and prohibition amounting to de-linking of drug policy from abstinence. It is contended that it is only a matter of time before that Rubicon is crossed.
\end{abstract}




\section{Keywords}

Harm Reduction Approach, Harm Eradication Approach, Sustainable Development, Penal Exceptionalism, Hybridization Approach, Health Indicators/Outcomes

\section{Introduction}

The Global Commission on Drug Policies ${ }^{1}$ took the position in 2015 that national drug control has to be aligned with the sustainable development goals approved by the member states. In so doing, it listed 17 developmental goals reflecting the different dimensions of the five sustainable developments: 1) social development; 2) economic development; 3) environmental sustainability; 4) peaceful, just and inclusive society; and 5) global partnerships. 2019 will sum up the 10-year global review of the Commission's 2009 political declaration and plan of action to "counter the world drug problem". In this regard, this article aims to establish that national drug approaches in Europe, Norway and Singapore though different are aligned in accordance with the sustainable development goals articulated by the Global Commission on Drug Policies in 2015.

This paper primarily aims to argue that though the harm reduction drug approach in the classic binary categorization of drug approaches reflects adherence to the sustainable development goals, drug approaches in Norway and Singapore are not contrary to sustainable development. The binary approach details national drug policies into two classifications: harm reduction and harm eradication with variances in both. The former is arguably said to be more aligned with the Commission's sustainable development goals, whereas the latter has been criticized for failing to consider the wider ramifications of drug use on health, society, family, marginalization, poverty, economic costs of drug use, rule of law, access to justice, role of the criminal justice system, etc.

A contextual and comparative analysis of the approaches in Europe, Norway and Singapore is offered to demonstrate that harm eradication drug policies coupled with increasing and strong harm reduction fundamentals such as, rehabilitation, science and evidence-based treatment interventions, reintegration of drug inmates into society, are consistent with the Commission's sustainable developmental goals, albeit to a varying extent. The paper anchors upon this comparative analysis of the harm reduction services available in these approaches to demonstrate the fine balance struck between prohibitionists and harm reduction fundamentals within each national drug approach to achieve alignment with sustainable development goals. National drug problems at times dictate a nuanced approach requiring a balance of both fundamentals which may not necessarily be inconsistent with the Commission's global drug policy. Harm eradication and reduction do not necessarily share a hydraulic relationship but ra-

${ }^{1}$ Hereinafter referred to as the Commission. 
ther serve different fundamentals within a system. As demonstrated by the policies adopted in Norway and Singapore, a desirable balance can be struck between retaining strong measures on the prevention, misuse and trafficking of controlled drugs and maintaining access, availability to controlled drugs, and harm reduction services such as evidence based treatment interventions. The issue often is whether an optimal balance has been achieved for sustainable development.

Two other ancillaries pertinent to sustainable drug approaches are also considered: health outcomes/indicators and delinking drug policy from abstinence. It is recommended that health and development indicators be used in metrics to judge success of drug approaches, given its impact on the five dimensions of sustainable development. It has been contended that prohibitionists and abstinence-based drug policies have worsened public health outcomes by failing to consider the negative externalities of such policies. In this regard the John Hopkins-Lancet Commission on Drug Policy and Health ${ }^{2}$ has recommended the provision of harm reduction services to drug users; regulation of drug markets; decriminalization of minor and non-violent drug offences to improve public health outcomes, amongst others (The Lancet Commission, 2016). Most countries have not used these indicators in its entirety, but have instead adopted a 'mix and match' approach of these indices to sustainably enhance harm reduction services to drug users.

Last, the approach taken by the Commission to sustainable development arguably requires a fundamental change in mindset in relation to drug use, control and prohibition. For some countries, the paradigm has shifted. Embracing harm reduction drug policies in some European countries and a softening of harm eradication policies coupled with increasing harm reduction services in the some of the South East Asian countries is a reflection of that mindset change. Yet, for many other countries, accepting the de-linking of drug policy from abstinence like in other behavior-related policies concerning consumption of liquor, cigarettes, etc, remains a difficult issue.

Nevertheless, there are many identifiable factors which may trigger a paradigm shift in favor of treating drug dependence per see and de-linking drug policy from abstinence like in other behavior related policies in time to come. ${ }^{3}$ Such triggers include globalization; negative externalities; ${ }^{4}$ draining national resources and government coffers; prevailing liberal attitudes amongst youth towards drugs use; increasing acceptance towards using controlled drugs for medicinal

${ }^{2}$ Hereinafter referred to as The Lancet Commission.

${ }^{3} \mathrm{As}$ is the case concerning liquor and cigarette consumption.

${ }^{4}$ This refers to negative externalities caused by prohibitionist and abstinence centric drug policies. An externality is the cost or benefit that affects a party who did not choose to incur that cost or benefit. A negative externality is an economic activity that imposes a negative effect on an unrelated third party. See Buchanan \& Stubblebine, 2006. Negative externalities include exacerbated public health problems, increased incarceration rates, under-treatment of chronic pain, corruption, compounding harm to users, decreasing quality of drugs made resulting in accidental overdoses or poisoning of drug users etc. See Friedman, 1998; Miron \& Zwiebel, 1995; and Kuziemko \& Levitt, 2004. 
purposes; ${ }^{5}$ and increasing awareness and better understanding of the science behind drug use and dependence (Lettieri, Sayers, \& Pearson, 1980), the last of which has led to the contention that current drug policies may in fact be coloured by ideas that are not scientifically grounded (The Lancet Commission, 2016).

\section{Sustainable Development Goals}

In 2015, the Commission took the position that drug control nationally has to be aligned with the sustainable development goals agenda approved by the member states. Seventeen developmental goals were listed as reflecting the different dimensions of the five sustainable developments social and economic development; environmental sustainability; peaceful, just and inclusive society; and the fostering of global partnerships (United Nations Office on Drugs and Crime, 2016). Given the scope and scale of the topic, this paper would place greater emphasis on some goals over others. The Commission's sustainable development goals take a multi-pronged and comprehensive approach by tackling both the root causes and consequences of drug issues. It is an evidence-based approach premised on the fact that for drug policy approach to be viable and effective, it must be sustainable and inclusive.

The social development goal focuses on getting countries to address the various sectors impacted by an individual's drug use. Drug use impacts the addict, his/her family, society and community at various levels. The World Drug Report takes the position that to have a sustainable and effective developmental drug policy, countries must deal with the causes and consequences of drug use in these sectors. For instance, to rehabilitate the addict, the country would need to deal with improving the health of the addict and provide guided employment opportunities so as to ameliorate the consequences of the vicious drug abuse cycle. Insofar as employability is concerned, countries are also urged to address the stigmatization surrounding drug use which enhances marginalization, poverty and drug abuse cycle. With respect to the familial sphere, countries are urged to address issues relating to family violence, the welfare of youth and children including their psychological and emotional development needs, financial problems, etc. (UNODC, 2016). As regards the community and the wider society, two issues were singled out. First, the need to deal with health matters relating to transmission of blood borne viruses due to unsafe drug practices. Second, the need to remove or work towards removing distinct barriers to the development of the individual and communities affected by drug use.

The economic development goal focuses on the need to address marginalization and poverty, which if left unaddressed will contribute towards perpetuating a cycle of drug abuse. The uprising of illegal drug markets and the economic costs of drug use are also important considerations. Marginalization was a real issue as it is both a cause and consequence of drug use. Economic costs, on the ${ }^{5}$ An example would be the use of cannabis for medicinal purposes. 
other hand, seen from the perspective of the state, translate into costs of treating and/or rehabilitating the addict, providing resources and infrastructure to support these ends, and costs involved incurred in incarcerating addicts (UNODC, 2016). These costs are often extensive and prohibitive, resulting in culmination of alternative and cost-effective options which ameliorates the strain placed on state resources. ${ }^{6}$ To this end, the loss of productivity due to drug use is also factored in the economic calculus.

Environmental sustainability will be not be discussed in detail given the scope of the paper, save as to a brief mention here. ${ }^{7}$ Environment sustainability as a development goal focuses on countries where problems relating to drug cultivation, trafficking, production and drug supply interventions ${ }^{8}$ have been encountered. It bears noting that these problems are no longer just confined to the aforesaid but has become a cross-jurisdictional issue given freedom of movement, reduction of trade barriers, enhancement of free trade zones and the production of synthetic drugs. Further, the production of plant-based and synthetic drugs has hidden environmental costs, as discharge of drug waste and or precursors and other chemicals required to process and manufacture such plant-based and synthetic drugs has hazardous repercussions to human health, urban and industrial environment, where such materials are illegally dumped, into or onto the ground, surface water, sewage systems and/or the sea by vessels (UNODC, 2016; see also EMCDDA \& Europol, 2009). ${ }^{9}$

Accordingly, issues relating to management of discharge of drug effluence and its effect on waste water management, including contamination of water due to drug waste and recycle of waste water, has compounded environment sustainability further. Water is a scarce resource and this situation will only exacerbate with global population increase and climate changes. Hence where reliance is on recycled or desalinated water, filtration standards of such water need to constantly innovate to ensure drug and pharmaceutical waste is properly filtered in accordance with international standards. Thus, the fact that Goal 6.3 of the sustainable development goal is stated to be achieved by 2030 comes as no surprise. By this goal, countries would need to improve the quality of water by reducing pollution, eliminating the dumping and minimizing release of hazardous chemicals and materials, halving the proportion of untreated wastewater and substantially increasing the recycling and safe reuse of water (UNODC, 2016) globally. For these reasons, environment sustainability will remain a live and important ${ }^{6}$ See Koman, 2018 for the genesis of harm reduction approaches.

${ }^{7}$ Environmental sustainability is deeply ingrained throughout the 2030 Sustainable Development Agenda. See United Nations General Assembly, 2015.

${ }^{8}$ Drug supply interventions include deforestations, etc and as such the focus is on South Americas, some of the south East Asian Countries such as northern parts of Thailand, Myanmar and Lao People's Democratic Republic. See UNODC, 2016.

${ }^{9}$ The environmental pollution discussed here is limited to illicit drug waste or chemicals used to produce synthetic drugs. However this does not diminish in any manner, another major issue (not the subject of this paper) that is threatening the rivers in the world, pharmaceutical effluence leaching into waterways seriously threatening the environment, ecosystems and rivers. See Phys.org, 2018. 
issue for most countries.

The fourth development goal focused on developing and sustaining a peaceful and just inclusive society has many facets (UNODC, 2016). To this end, some of the issues considered when evaluating the sustainability of the various drug approaches are: First, the need to deal with forms of violence in connection with drugs, such as, property and domestic violence as a result of drug use, use of violence to get drugs, intra drug criminal groups dealing with trafficking and production, terrorism and insurgency funded by illicit drug trade etc. Second, the role of rule of law and access to justice in ensuring fairness and equality of the law. Role of the criminal justice system, its influence and how it is influenced by developments in drug sectors are fundamental given the impact of law enforcement on drug prices and markets, the efficient or inefficient allocation of resources arising from imprisonment and its alternatives. Only some of these issues will be considered in this paper.

Last, the goal of fostering global partnerships relates to the provision of mutual assistance for development and for drug related sectors to redress any imbalances within. This will be addressed further in the 2030 Agenda and will not be the focus of this paper. ${ }^{10}$

The sustainability and compatibility of drug approaches in Europe, Norway and Singapore will be examined in this context.

\section{National Drug Approaches and Their Compatibility with the Sustainable Development Goals in Europe, Norway and Singapore}

\subsection{European Approaches}

Generally, the European jurisdictions tend to take a health and human centered approach towards drug issues and policies which is in alignment with the Commission's sustainable developmental goals. The core of the European approach is premised on treating the source of the problem, i.e. addiction, whilst also dealing with the consequences of drug use. It views drug addiction primarily a social problem in a medical context, thus embracing a rehabilitative model. Insofar as criminal law is concerned, the European model is generally consistent with the Commission's two-step decriminalization process, where first, low level consumption, possession and/or use is decriminalized and replaced by administrative consequences, medical treatment and/or social measures and second cultivation, couriering and supply by low level actors for purposes of consumption and/or possession for personal use is likewise decriminalized or falls under reduced penal laws (Global Commission on Drug Policy, 2016; Koman, 2018).

The European model has abolished the death penalty as a punishment for drug transgressions and low level drug offences such as consumption and possession has either been decriminalized or falls under reduced penal laws. ${ }^{11}$

${ }^{10}$ These imbalances are addressed in the 2030 Agenda. See United Nations General Assembly, 2015.

${ }^{11}$ See also Articles, 36(1) (b) and 38(1) of the Single Convention on Narcotic Drugs of 1961 (as amended by the 1972 Protocol on Single Convention). 
Though some distinction is made between hard and soft drugs in the application of the drug laws and penalties, generally alternative and additional measures are provided to low level drug offenders caught for consumption and/or possession of drugs for personal use. ${ }^{12}$ As to what constitutes the alternative measures varies between the European States but in general there are two variants. First, where countries have decriminalized low level drug consumption and/or possession, they may offer community-based treatment programs, probation, and counselling and therapeutic interventions as direct alternatives to legal sanctions (Koman, 2018). Such measures are administered by specialized drug courts. The other variant sees similar rehabilitative measures offered as alternative options within the criminal justice system instead. ${ }^{13}$ Where such options are elected, criminal proceedings are held in abeyance till satisfactory completion of the rehabilitative and treatment programs. ${ }^{14}$ In both situations ample resources are spent on treatment, counselling and medical interventions, focusing on treating the addict and addressing the cause of the problem and hence reducing recidivism sustainably (Stevenson, 2011).

The European approach directly tackles the addict, their families, society and community at various levels, addressing the social development goal. First, in approaching the drug issue from the medical context and offering alternative measures, community-based treatment programs, evidence-based medical interventions, counselling and probation, the European counterparts are dealing with the root source of the problem: addiction and its consequences. Harm reduction services such as such as needle and syringe exchange programs; provision of clean and sterile injection equipment; use of non-injected opioids; opioid substitution therapy ("OST") and other drug dependence treatment; HIV testing and counselling; antiretroviral therapy; condom programs; providing education and targeted information for drug users are well provided. ${ }^{15}$ This is in tandem with the approach advocated by the World Drug Report which takes the position that a country can only achieve a sustainable and effective developmental drug policy when it deals with consequences of drug use, amongst others. Second, by offering administrative or alternative sanctions, the focus is on achieving compliance with the treatment programs and avoiding a criminal record to enhance employability prospects. Focusing on the health and employability of the addict is instrumental to breaking the vicious cycle of abuse/use which is an important precursor to ameliorating marginalization and stigmatization. Conceptualizing ${ }^{12}$ In some European countries such as Czech Republic and Germany, in cases of cannabis, such alternative measures are also offered to "low level cultivators, couriers and suppliers" who engage in such activities to feed their drug habits. See Koman, 2018.

${ }^{13}$ This is advocated in the United Kingdom and some European countries, such as Malta and Portugal. Countries such as France, Luxemburg, Romania, Austria, Greece, Latvia and Netherlands offer such measures with variations. See Koman, 2018.

${ }^{14}$ See, e.g., Suchtmittelgesetz $\$ 39$ (Austria); Trestní zákon art 48 (Czech); Reglamento Penitenciario art. 182 (Spain); Gesetz über den Verkehr mit Betäubungsmitteln (Betäubungsmittelgesetz-BtMG) $\$ 35$ (Ger.); Krimināllikums $\$ 55$ (Lat.); sr Art. 14a (Neth.). Specifically, in Austria, since 2008 it is mandatory to suspend the sentences if the prescribed legislative conditions are satisfied.

${ }^{15}$ This will be addressed under section IV of this paper. 
drug addiction in the medical context, coupled with decriminalization ameliorates the social stigma associated with the drug issue. This is further enhanced by the work of the drug courts done in this area.

Countries which have drug courts are able to mete out a comprehensive approach towards drug infractions as these courts work closely with other agencies in handling treatment options. ${ }^{16}$ The effectiveness of these drug courts are achieved through either having a medically trained judge or partnering with a team of correctional, health and welfare professionals to monitor and review the ongoing process and efficacy of the treatment plan. An effective treatment plan translates to a treated "addict" and hence one less in the 'drug society'. The review period ensures that the addict receives all necessary support and continuity to facilitate effective treatment. The system has been designed to facilitate 'buy in' by the addict and incentivize them to follow through with participation, treatment and completion to avoid the threat of legal sanctions. Compliance or lack thereof would be monitored by the drug courts through regular testing of the drug addicts and submission of progress reports (Koman, 2018).

Granted, the abovementioned protocols are time consuming and costly in comparison to the regular court system of handling drug addicts. However, the drug court process is outcome-driven to reduce recidivism. The alternative measures offered are effective in dealing specifically with the nuances of the drug offence and offender (Koman, 2018). Such targeted, structured and customized treatment options ensure continuity in effectively dealing with the offender and their overall wellbeing in a sustainable manner. While it is a costly adventure, meta-analysis in the United States has demonstrated that drug court programs do contribute to the reductions in the rates of drug abuse and drug related crimes as well as improvements in the overall well-being of the offender, including their psychological and emotional development needs (Mitchell, Wilsonn, Eggers, \& MacKenzie, 2012). An individual treated of his/her addiction returns to the society as a functional economic unit.

All of the above facilitates a peaceful, just and inclusive society when access to justice is enhanced, structural burdens on the criminal justice system's prison resources are reduced and resources are redirected towards alternatives to imprisonment and harm reduction services instead. As a matter of fact, the criminal justice system, inter alia, has been increasingly influenced to create drug courts to specifically address the needs of the addicts and the societal concerns to this end. This further impacts the role of law enforcement which generally influences drug markets and their pervasiveness.

The offering of various treatment options such as opiate treatment programs and substitution treatment options acknowledges the difficult issues in treating addiction and ensuring the wellbeing of the addict in accordance with the sustainable development goals. Though there is a call for such treatments to be expanded, with proper legal foundation and less restriction placed on the admis-

${ }^{16}$ Norway and Belgium have specialized drug courts which adopt this comprehensive approach. 
sion criteria and regulations (EMCDDA, 2015a), the current available treatment options along with needle exchange programs do make a valiant attempt to curb unsafe drug practices and prevent transmission of blood borne viruses.

The European model is also economically sustainable. Comprehensive efforts to reduce or curb drug addiction in this model are instrumental in reducing the economic footprint of drug use, in terms of curbing productivity loss and the long-term state costs in assisting drug users. In countries where drug infractions are decriminalized, obvious and automatic reduction of the load on the criminal justice system and prison resources have been observed. Such saved resources can be efficiently allocated towards more deserving causes such as catering to the rehabilitative needs of the addict (EMCDDA, 2015a).

The formation of illegal drug markets in some European countries has to a certain extent been affected by the legalization of certain hard core drugs such as cannabis. ${ }^{17}$ Such legalization of hard core drugs for medical purposes have also been considered in some Asian countries. ${ }^{18}$ Such efforts do tend to lead to demand reduction in the illegal drug market and consequently drug prices and the lucrativeness of such markets. Besides negative externalities created by illegal drug market ${ }^{19}$ and prohibitionists drug policies are also reduced in this model.

Given all of the above methods and strategies, it is imperative that drug policies do attempt to remove or work towards removing distinct barriers to the development of the individual and communities affected by drug use, consistent

${ }^{17}$ In the case of cannabis, there is currently no harmonized law in the European Union addressing it. Administrative or criminal offences with respect to drug offences including cultivation remain the responsibility of individual member states. In Belgium, cultivation of one plant is a minor offence resulting in a fine. In Netherlands, though cultivation of cannabis is not decriminalized, the police has the discretion to confiscate small amounts of cannabis or plants grown for personal use and the owner may avoid prosecution by voluntarily handing the drugs over to the authorities. In Cyprus, cultivation of three or more plants is presumed to be a supply offence. In Denmark, prosecution guidelines consider 100 grams of cannabis plants as the upper limit to be considered for possession for personal use. In the United Kingdom, the 2012 drug offences sentencing guideline proposes the starting point as a fine or community order for the cultivation of nine plants. Portugal, which has been a trailblazer for decriminalizing drug use and personal possession in 2001, cultivation of any amount, even for personal use, still remains a criminal offence. Likewise, Croatia has specifically excluded cultivation or owning one plant for personal use from decriminalization and the offence is punishable with a sentence ranging from six months to 5 years of imprisonment. Cultivation in Finland is also considered a narcotics offence. In Spain, since 2015 cultivation for personal use in places visible to the public is an administrative offence and is punishable by a fine. In Germany, seriously ill patients are allowed to grow, buy and consume their own cannabis under a special license, and medical marijuana is legalised in the Czech Republic. See EMCDDA, 2017; Khalip, 2015. In the United States, currently 23 states allow for private cultivation of cannabis, though the permissible amount varies between states. See Leafly, n.d.

${ }^{18}$ Use of cannabis for medical purposes has been legal in Thailand since 2018 and at present, Indonesia and Malaysia are considering similar legalization of medical marijuana. See Paulo \& Woo, 2019.

${ }^{19}$ This refers to negative externalities caused by prohibitionist and abstinence centric drug policies. An externality is the cost or benefit that affects a party who did not choose to incur that cost or benefit. A negative externality is an economic activity that imposes a negative effect on an unrelated third party. See Buchanan \& Stubblebine, 2006. Negative externalities include exacerbated public health problems, increased incarceration rates, under-treatment of chronic pain, corruption, compounding harm to users, decreasing quality of drugs made resulting in accidental overdoses or poisoning of drug users etc. See Friedman, 1998; Miron \& Zwiebel, 1995; and Kuziemko \& Levitt, 2004. 
with the sustainable goals.

\subsection{Norway's Dual Approach and Penal Exceptionalism}

Norway's approach, often termed by some as exceptional, arguably deserves special mention given its evolution. Norway's approach to drugs from the 1960s to 1984 was premised on harsh penal measures. Drugs were perceived as nothing but a threat and menace and the maximum legal penalties only grew harsher during this period. Characterized by maximum prison terms and radical criminal investigation methods for drug related offences, Norway's penal system for drug related offences was then geared towards achieving a drug free society. ${ }^{20}$ The primary aim was to eradicate the illegal sale and trafficking of drugs, whilst trying to understand the cause of the drug use.

The duality, as Norway then was grappling with, was whether the underlying cause of drug use/abuse was a disease per se and/or symptomatic of underlying pressures, social, economic or personal. It was this wanting and mindfulness to understand the causes of drug use that spurred Norway to tackle the drug policy at multiple fronts with success. Though the drug issue was primarily then seen as a criminal infraction deserving punishment, obscuring the consideration for treatment of drug users, its punitive drug legislation based on preventative and deterrence principles is mainly aimed at dealers and traffickers (Skretting, 2014). The consumption and possession of drugs for personal use, including that of heroin and cocaine are instead typically sanctioned with a fine and/or a lighter imprisonment term of up to 6 months (Lov om legemidler $\mathrm{m} \mathrm{v} \$ 24$; \$31). Cognizant of the underlying pressures resulting in drug abuse, in 1979, Norway decided to strengthen its social fabric at both the community and family level by increasing funding to the social welfare system (Skretting, 2014). ${ }^{21}$ The start of this process was an important catalyst to increasing the provision of harm reduction services in later years.

By the mid-1980s, there was a paradigm shift in attitude towards drug users. From being considered a menace they were increasingly seen as individuals deserving social and health care in the form of harm reduction services rather than punishment. Following the increase in the rate of HIV infections in the 1980s, free needle exchange programs sprouted out of necessity in 1988 to curb the spread of communicable diseases. With a rise in overdose fatalities, the provision of methadone substitution treatments ${ }^{22}$ and supervised injection rooms ${ }^{23}$ soon became part of the harm reduction services offered. Low threshold health services for substance abusers were also provided at local level by the municipalities (Skretting, 2014). Even local drug parks started to feature in which drug users

\footnotetext{
${ }^{20}$ During this period, the maximum prison terms for drug related offences rose from 6 months to 21 years. See Hauge, 2009.

${ }^{21}$ This attitude to improving social fabric was further reinforced in 1985.

${ }^{22}$ The first pilot program started in 1994 and thereafter became a regular supplement seen as part of the main stream therapeutic measures offered for drug treatment. See Skretting, 2014.

${ }^{23}$ This was first implemented first in 2005. By the Drug Injection Rooms Act in 2009, such services were made permanent.
} 
would not be "taken in" by authorities for their "drug recreational activities" (Hauge, 2009).

By the 2000s, drug abuse was seen as a medical dependence issue as opposed to abuse and it began to be treated in the same context as alcohol dependence, deserving of medical treatment and aftercare. Seen in this context, the National Health Service, NHS, became the first port of call for treatment (Skretting, 2014; Stoltenbergutvalget, 2010). Thus, by the 2000s, Norway was already treating drug dependence like any other behavior related issues, such as alcoholism. In 2012, Norway stipulated its end goal as reducing "the negative consequences of substance abuse for individuals, third parties and society" and to "give the population more years in good health" 24 eschewing its former goal to achieve a "drug free society" (omsorgsdepartement, 2012). Norway's progressive, human and health centric drug goal is extremely impressive given that only from the 1960s to the 80s its drug policy was regarded as being the most repressive in Western Europe. However, Norway's duality in treating drug dependents with harm reduction services and imposing strict preventative and deterrence drug laws on dealers and traffickers remain till today. The maximum penalty in the Penal Code for drug related offences remain at 21 years (Lov om straff $\$ 232$ ).

However, notwithstanding the paradigm shift in the state attitude towards drug users and drug dependency, the Norwegian government in 2008 rejected calls for decriminalization, citing the extensive indirect harm inflicted by drug users on their families, the wider economy and society such as general law and order etc. Additionally, there remains the concern that decriminalization may have negative consequences, such as reducing the motivation of addicts to seek rehabilitative treatment services, not to mention possible ramifications on anti-drug measures in place to dissuade young individuals from drug consumption (politidepartement, 2008). In all, the government was not satisfied that decriminalization will reduce the drug problem (omsorgsdepartement, 2012). It could also have been possible that drug decriminalization was perceived as irresponsible drug liberalization by the electorate. As such, legal punishment must remain a strong deterrent to influence behavior. By the way, Norway does have one of the harshest punishments for drug related offences in Scandinavian countries with maximum penalties of 21 years in the New Penal Code.

Much has been said about Norway's prison system. Scandinavian countries ${ }^{25}$ have been touted as boasting penal exceptionalism in an era of penal excess. Penal exceptionalism is characterized by low imprisonment rates and humane prison conditions which are unusually favorable, as approximate to life outside as far as possible (Pratt, 2008a; Pratt, 2008b).

The classic proposition is that correctional facilities are inherently punitive, correction inclined and outcome driven. Each country's penal institutional structure has a value orientation-it can be inclined towards security or social ${ }^{24}$ Norway also moved to terming all abuse as dependence and drugs and alcohol dependence were classified generally as substance dependence comprehensively.

${ }^{25}$ Consisting of Norway, Sweden and Denmark. 
harmony or even a combination of both with a weaker or greater orientation towards either (Crewe \& Liebling, 2012). Norway's prison system appears to be oriented towards harmonistic values such as peaceful coexistence; mutual respect; empowering dignity; empowering and developing each individual's potential; sharing resources; and mentally "de-carcerating" inmates to achieve as much normalization as possible and to self-govern through conditioning. Hence, the Norwegian correctional facilities are said "not to punish less but to punish better" (Foucault, 1995). Premised on the principles of restorative justice and rehabilitation, Norway's correctional institutions use the import model. By this model, external providers are responsible for offering the same type of services to inmates in prison as provided to regular citizens outside the prison (Kriminalomsorgen, n.d.). Thus, health and other services remain provided to the same standards, ensuring equality and parity in treatment of its citizens regardless of incarceration.

Norway has both closed and open prisons. In the open prisons, ${ }^{26}$ the living conditions mirrored as much as possible to outside conditions. Inmates have a choice between engaging in paid work or study in or outside, the latter being reserved for inmates who have earned the trust. There is a freedom of movement within the penal institute. All of the above serves to act as a "socialization mechanism", acclimatizing the inmate to the outside world by enabling and empowering smooth transition from the penal institute to the outside world upon release (Shammas, 2014). ${ }^{27}$ Perhaps that may be the reason for having one of the lowest recidivism and incarceration rates in the world (Sterbenz, 2014; Jilani, 2011)..$^{28}$

Insofar as drug inmates are concerned, the import model likewise applies to them. As stated above, since the municipality is responsible for the healthcare treatment services and the NHS is first port of call of treatment, the municipality in which the prison is located organizes the specialized health care services for drug inmates, including interdisciplinary specialized drug treatment. Healthcare staff responsible for such treatment are trained on drug related problems. Harm reduction services provided in such settings include counselling; motivational interviewing; OST, testing and counselling for infectious diseases; education and training; and preparation for release. Prisoners are given disinfectant material for their syringes and needles to prevent spread of communicable diseases. Testing; risk assessments; treatments; counselling; and educational information are also provided to this end. Last, to ensure smooth provision of adequate health services to drug dependents and follow up, a reintegration coordinator

\footnotetext{
${ }^{26}$ Open prisons accounts for one third of Norwegian prisons.

${ }^{27}$ Though open prisons are touted as humanized and exceptional, they have their fair share of issues. For instance, Shammas (2014) indicates that inmates who are in such prisons do to a significant degree shoulder the burden of self-control, suffering anxiety when transitioning from a closed to an open prison, ambiguity over beneficial goods and privileges and confusion in roles etc. See also Mathiesen, 2012.

${ }^{28}$ Other countries have considered emulating elements the Norwegian prison model given its success rates. See Jewkes \& Gooch, 2019.
} 
ensures binding collaboration between the correctional service and the public agencies when the inmate is released (EMCDDA, 2018c). The prisons also have drug rehabilitation units within to motivate and prepare imprisoned drug users for further treatment and rehabilitation upon their release. ${ }^{29}$ All of the above only assures a comprehensive, human and health centric rehabilitative system in accordance with sustainable development.

Norway's system seems to have worked well thus far. However, there are challenges to its system of exceptionalism. First, there is a rise in punitive laws premised on increasing political rhetoric on crime, punishment and law and order. ${ }^{30}$ Second, there has been a downsizing of fiscal expenditure for rehabilitative policies due to reducing homogenous population and increasing ethnonational class lines (Shammas, 2014). About 30.9\% of the prison population are foreigners (World Prison Brief, n.d.) and this has resulted in a dual prison system, one catering to citizens and another for foreigners (Ugelvik, 2013). Whether this two-track system will result in a difference in treatment and provision of services remains to be documented. The rising wave of immigrants in Norway has also changed the homogeneous population scene which was the cornerstone of the egalitarian welfare system and rehabilitative penal state. Rising immigration levels appears to have titled the system towards a punitive penal state from assistive social state (Shammas, 2016). Third, the transformation of the welfare state towards "neo-liberal restructuration" has resulted in growing socioeconomic inequality, and the move towards market orientation of public sector has increased dependence on private providers of welfare state services, etc. (Shammas, 2016). Last, the increasing polarization of income and wealth concentration and a corresponding reduction in welfare and social policies has led to a rise in individualism. The practice of exceptionalism requires a strong welfare state and egalitarian values and perhaps these would be the challenges in continuing to apply such a model in Norway and in applying such a model in other countries absent these fundamentals.

\subsection{Singapore's Hybrid Approach}

While Singapore's drug model appears to be largely that of the harm eradication model, it is in fact more of a hybrid straddling between harm eradication and reduction fundamentals, with the supply reduction strategy underlying the harm eradication fundamentals and the demand reduction embodying the harm reduction fundamentals. Seen in this context, the hybridization arguably ticks ${ }^{29}$ Not withstanding the purpose of such units, it has been stated that the hybrid role of prison officers in such units do not provide a conducive role for rehabilitation of drug inmates as it leads to amongst others, arbitrary decision making resulting in breaches of equality principle between prisoners and thereby affecting the dimension of imprisonment and quality of life and behavior in prison. It was also mentioned that such hybrid roles increase the discretionary powers of the officers, social control by staff, in turn weakening prisoner protection and blurs prisoner roles etc. See Mjåland \& Lundeberg, 2014.

${ }^{30}$ Since the $22^{\text {nd }}$ July 2011 terrorist attacks in Norway, there has been an increase in police proactive powers extending into the fields of organized crime and drug offending. See Husabø, 2013 \& Shammas, 2016. 
most of the sustainable goal boxes.

At the eradication end, Singapore has not adopted the Commission's two step decriminalization process and has no intention of doing so for now. Therefore, consumption, possession and/or use of drugs, low level or otherwise is criminal and liable to penal consequences under the Misuse of Drugs Act ("MDA"). Likewise for cultivation, couriering and supplying of drugs by low level actors for purposes of consumption and/or possession for personal use (MDA $\$ 8(\mathrm{a})$-(b); §5; \$17; \$18)..$^{31}$ Individuals who have tested positive for unauthorized consumption of drugs can be detained under executive order (MDA \$34) for mandatory treatment and supervision (MDA $\$ 31(1)$; 31 A (1)). Death penalty or life imprisonment with mandatory canning are applicable for the trafficking, manufacturing, importing or exporting of controlled drugs of certain quantities (MDA §5; Second Schedule). Exceptions to the death penalty but are very narrow and limited. ${ }^{32}$ When the exceptions do apply, life imprisonment and canning of not less than 15 strokes of the cane may be imposed in the alternative (MDA $₫ 33 B(1)(a))$.

One other point remains to be mentioned with respect to trafficking. Given the difficulties in proving the trafficking of drugs, two presumptions of law operate against a trafficker in possession of controlled drugs of specified quantities (MDA Second Schedule). When in such actual or constructive possession (MDA $\$ 18(1)-(2)$ ), the trafficker is presumed to be trafficking in those drugs. ${ }^{33}$ Additionally by reason of possession, the trafficker is presumed to know the nature of those controlled drugs. Both presumptions are rebuttable and the burden is on the trafficker to rebut on a balance of probabilities.

Singapore is still trying to achieve a drug free society and the laws and policies are geared to this end. ${ }^{34}$ Therein lies one fundamental distinction with the European model which appears to have accepted that it is unrealistic to achieve a drug free society given the proliferation of drugs, synthetic or otherwise, as well ${ }^{31}$ The Central Narcotics Bureau has also been consistently updating the list of controlled drugs under the Misuse of Drugs Act. From $1^{\text {st }}$ May 2019, five new psychoactive substances: Adamantyl CHMINACA (SGT-37); 3,4-DCMP; 5-Fluoro-cumyl-PICA; 5-Fluro-SDB-005; and SDB-005 which were previously listed in the Fifth Schedule, would be reclassified as Class A controlled drugs in the First Schedule. In addition, a separate substance known as lisdexamphetamine was also listed in the First Schedule as a Class A controlled drugs. Having been listed as Class A controlled drugs, the trafficking, manufacture, import, export, possession or consumption of these substances would constitute an offence under the MDA. The Fifth Schedule on the other hand was enacted on 1 May 2013 to allow the Central Narcotics Bureau to seize the particular listed substances in order to restrict their circulation while research and industry consultation are conducted, which are necessary before the substance is classified as a controlled drug. See Central Narcotics Bureau, 2019b.

${ }^{32}$ See MDA $\$ 33 B(1)-(2)$. The death penalty can only be displaced under either of the two circumstances. First, when the public prosecutor issues a substantial assistance certificate when a trafficker renders substantial assistance to the Central Narcotics Bureau in disrupting drug trafficking activities. Whether to issue such a certificate is within the discretion of the public prosecutor, solely. Second, when the trafficker suffers from a state of diminished responsibility i.e. suffers from an abnormality of mind that substantially impaired his mental responsibility for his acts or omissions in relation to the offence.

${ }^{33}$ This is loosely known as trafficking by possession in legal parlance.

${ }^{34}$ This is consistent with the goal set by the Association of Southeast Asian Nations (ASEAN) to achieve a "drug free ASEAN" by 2015. See UNODC, 2008. 
as the changing mindsets to drug use and abuse. ${ }^{35}$ Another important distinction, ${ }^{36}$ inter alia, would be that drug use in Singapore is categorized as a social and behavioral deviance warranting custodial and penal sanctions, like any other criminal infractions (Yew, 1999; Koman, 2018). Hence, preventative drug education, deterrent punishment and strong law enforcement are fundamental features of Singapore's system.

In 2018, further amendments were made to the MDA, in recognition of the critical role of the family and the need to protect children from harmful influences of drugs. By these amendments, a positive obligation is now placed on drug consuming parents to protect children from contamination of drug habits. Hence, it would be an offence under the new section $11 \mathrm{~B}(1)$ for an adult to recklessly leave controlled drugs or drug paraphernalia within easy access of a child knowing that a child of less than 16 years is present in that place (MDA Amendment Act $2019 \$ 3) .{ }^{37}$ Second, by these amendments, a positive obligation is placed on an adult or parent of the household to take reasonable steps to stop a young adult from consuming drugs. Thus, it is an offence under the new section $11 \mathrm{~B}(2)$ for an adult that permits or does not take reasonable steps to prevent a young person of less than 21 years from consuming drugs within their possession (MDA Amendment Act 2019 \$3). The section carries a deterrent sentence of a maximum imprisonment of ten years for first time offenders. Consistent with the sustainable development goals, these measures attempt to curb or arrest contamination of drug habits within a household and also ensure that the welfare of children and youth are not undermined.

Singapore premises its stand on a firm grasp of supply and demand reduction policies. ${ }^{38}$ Supply reduction is to be achieved through strict laws against trafficking, manufacture and import of controlled drugs listed in First Schedule of the MDA. Demand reduction, on the other hand, is to be achieved via rehabilitation; evidence-based treatment interventions; education; vocational training; constant supervision; and aftercare monitoring of the addicts. It is the latter that aligns with most of the sustainable development goals.

The latter hybrid part of the Singapore system most aligned with the sustainable development goals comes from comprehensive and structured rehabilitation aimed at ensuring the drug user/abuser is rehabilitated and reintegrated into so-

\footnotetext{
${ }^{35}$ This position is also consistent with the Commission's view. See Global Commission on Drug Policy, 2011; United Nations High Commissioner for Human Rights, 2015. See also Adili Chibuike Ejike v PP [2019] SGCA 38. Note it has been held in a later case that presumptions cannot be applied where the prosecution has conceded that the defendant did not have knowledge of the presence of the drugs.

${ }^{36} \mathrm{As}$ stated above, drug use and abuse in Europe is seen from the medical context.

${ }^{37}$ While the Misuse of Drugs (Amendment) Act 2019 has been passed, only selected provisions have their date of commencement stipulated as $1^{\text {st }}$ April 2019. The remaining provisions, which includes the new section 11B offences, would only take effect in the second half of 2019. See Ministry of Home Affairs, 2019.

${ }^{38}$ Curbing supply of drugs via strong laws is premised on preventative, punitive and deterrence principles. Demand reduction on the other hand is to be achieved via rehabilitation of drug addicts via treatment and evidence-based treatment measures. See Koman, 2018.
} 
ciety. Holistically, the entire rehabilitation process is well thought, human and health centered. Unlike regular prisoners, drug inmates are housed in Drug Rehabilitation Centers ("DRCs"). ${ }^{39}$ Singapore clearly recognizes the impact drug use has on social and economic development and resources are not spared in achieving this objective. Its agenda for a drug user is clear: to rehabilitate, reintegrate into society, be gainfully employed and accepted by society. The aim is fundamentally to rehabilitate.

First, unlike regular imprisonment, the detention period is focused on four main goals: detoxification, recuperation and transfer, physical fitness and rehabilitation (Yew, 1999). Hence, there is a duality of purposes behind detention: to serve their punishment and be rehabilitated at the same time. The number of inmates admitted to DRCs has been on a steady rise (Data.gov.sg, n.d.-a). ${ }^{40}$

Second, DRCs are available to first to third time offenders of drug offences. Previously, DRCs were only available to first and second time drug offenders, and third time offenders were subjected to long term imprisonment. However, in 2019, it was announced that the DRC Long-Term Imprisonment (LT) regime would be amended to allow third time offenders rehabilitation under the DRCs, provided concurrent offences have not been committed (Singapore Parliamentary Report, 2019). The law would also be amended to provide for a longer maximum duration in the DRC so that hardened drug addicts get longer and more intensive rehabilitation treatment, increasing the time to practice the skills taught and their chances of rehabilitation and to break the cycle of abuse. ${ }^{41}$ As a side note, the DRCs caters to high risk abusers. Young abusers who are evaluated to be of low to moderate risk are placed in the Youth Enhanced Supervision scheme and in the Community Rehabilitation Centre respectively. The former would be required to report for regular urine testing and receive counselling from social service agencies to address the cause of their addiction. The latter are placed in a residential program which gives a structured environment for rehabilitation. They are allowed to continue with work and/or study commitments during the day and are provided with intervention and life skills programs to deal with risk of re-offending (Ministry of Home Affairs, 2016). Under the new enhanced rehabilitation scheme, first time abusers who do not have other criminal charges and who have been assessed ${ }^{42}$ to be of low-risk of further abuse, will be put on an Enhanced Direct Supervision Order, a non-custodial supervision order for a period of up to five years (Singapore Parliamentary Report, 2019). These individuals would be assigned a case manager to provide support to them and their families. Needless to say, first time or subsequent abusers assessed to be of moderate or high risk of further abuse will be put through the DRC regime ${ }^{39} \mathrm{DRCs}$ are institutionalized under the Singapore prison system and are state funded. See Yew, 1999.

${ }^{40}$ See also Data.gov.sg, n.d.-b for the dataset on the number of inmates released from DRCs.

${ }^{41}$ Section 18 of the Amendment Act increases the maximum detention period under section $34(h)$ of the MDA from three to four years. However, this provision would only take effect in the second half of 2019. See Ministry of Home Affairs, 2019.

${ }^{42}$ These assessments are done by the CNB. 
instead.

The various programs and orders segregating the offenders, young or otherwise, reflects the need for customized treatment and intervention programs to deal with different types of drug offenders and also to prevent the spread of the drug problem internally within these categories. The segregation also reduces negative social modelling and sub-culture within. For like reasons, hardcore and non-hardcore addicts are segregated within the DRCs, and are subjected to appropriate counselling sessions, rehabilitative measures, enhanced or otherwise and evidence-based treatment interventions respectively (Yew, 1999). It must be noted that the counselling sessions are also provided to family members so that their welfare is not undermined and so that they can provide the necessary critical family support to the addict to enable them to break the cycle of abuse. Hence fostering inclusiveness.

It is noteworthy to mention that in furtherance of recognizing the critical role of the family in supporting a youth abuser's rehabilitation, the parents or guardians of youth abusers ${ }^{43}$ under the Central Narcotics Bureau's ("CNB") supervision order will soon be mandated under section 34A of the MDA to attend the counselling sessions with their child (MDA Amendment Act 2019 \$19)..$^{44}$ Parents or guardians who fail to comply without reasonable excuse would be liable to an offence punishable with a fine or be ordered to attend the counselling sessions.

Third, the appropriate intervention programs within the DRCs are customized to address the specific risks and needs of the inmate during the detention period, to enhance their chances of employability and to reduce recidivism. Intervention programs range from psychological-based correctional and family programs; confidence building sessions; therapeutic interventions; counselling sessions; and skills training under programs initiated by the Singapore Corporation of Rehabilitative Enterprise (Jalelah, 2013; Koman, 2018). Scenario-based simulations are engaged for inmates with higher risk of reoffending. The latter is particularly concerned with equipping them with strategies to turn away from drugs and increase their self-worth (Ang, 2019). These programs work on changing mindsets towards drug use and imparting practical skills to manage difficult situations and work towards a drug free lifestyle. It is patent that there is a clear recognition that specialized rehabilitation and intervention programs treating drug addiction and changing mindsets of drug addicts is a constant work in progress peppered with relapses. The release of hardcore addicts into society is calibrated carefully to ensure their smooth transition back into society.

Next, the drug addict'/user's progress is reviewed every six months by the DRC Committee, chaired by a medical practitioner. This demonstrates the clear recognition of the need for health and evidence-based treatment measures (Yew, 1999).

\footnotetext{
${ }^{43}$ This refers to persons of less than 21 years of age.

${ }^{44}$ This provision would only take effect in the second half of 2019. See Ministry of Home Affairs, 2019.
} 
Last, the release process is carefully calibrated to facilitate smooth transition from the DRCs into society. Hence, upon completion of the detention at DRC, the addict is placed on a community-based program ("CBP") which could involve being placed in a halfway house, being released in the day from the DRC or allowed back home under the residential scheme with electronic tagging. During this period, vocational training and work during the day can be undertaken whilst continuing with rehabilitation. The halfway house scheme provides social support via counselling; discipline; and regular urine testing whilst at the same time reintegrating the addict into society via vocational training and work (Ang, 2019; New govt-run hallway house for ex-offenders to be ready by 2018, 2014; Singapore Corporation of Rehabilitative Enterprises, n.d.). Upon completion of the $\mathrm{CBP}$, the individual progresses to the supervision phase where he/she is required to report regularly to the $\mathrm{CNB}$ for urine or hair testing. For enhanced rehabilitation and follow up, supervision phase under the new amendments have been increased from two to five years. The supervision phase acts as a further crutch to ensure that the individual is aided in his/her efforts to break the cycle of addiction and does not fall through the cracks. ${ }^{45}$

Such a system allows the reintegration process to be calibrated at a pace that is suitable for the addict. The fact that addicts are given evidence-based treatment measures; counselled; and monitored pre- and post-release via the structured halfway house program demonstrates a strong and consistent commitment on the part of government and non-governmental agencies to work together in partnership to rehabilitate and reintegrate addicts into society in a sustainable manner (Koman, 2018).

All of the above demonstrates that the rehabilitation within the DRC focuses clearly on the health and employability of the drug addict/user. Concerted efforts are made to ensure that the drug addict/user is not marginalized and stigmatized by providing employment opportunities. Additionally, detention at the DRC does not result in a criminal record. The process at the DRC equips the drug addict/user with psychological and developmental skills to integrate into the society, reduce recidivism and remain gainfully employed. The undertaking to place the reformed individual in a structured program of integration into society and employment recognizes the economic costs of drug use, such as productivity loss if left unaddressed. Drug abuse related barriers to the development of the drug addict/user and the community are alleviated by this process of rehabilitation. Further, such rehabilitation methods also seek to break the cycle of re-offending and/or committing related offences.

National drug approaches in Europe, Norway and Singapore are aligned in accordance with the sustainable development goals. The manner in which it is assessed to be sustainable may differ but it is arguably consistent albeit to a varying extent. The rehabilitative European model ticks most, is sustainable and inclusive. It is holistic, health and human centered. Commission's two step de${ }^{45}$ However, drug abusers who commit other criminal offences and harm to society are dealt with strictly with imprisonment and caning. 
criminalization process with alternative measures are adhered to ensure comprehensive, effective and sustainable rehabilitation. Their harm reduction services are consistent with effective and sustainable drug policy. Notwithstanding there is a call for even more services to be provided. All in all, their policies do attempt to remove distinct barriers to the development of the individual and communities affected sustainably. On the other hand Norway's criminalization of controlled drugs, drug related activities and drug use remain. However its preoccupation with the causes of drug use led to the strengthening of its social fabric resulting in an increase in social funding which catalyzed the provision of extensive harm reduction services in community and in prison sustainably. Norway has been able to delink its drug policy from abstinence as it perceives drug use like any other behavior related problem. In prison, Norway boasts penal exceptionalism, characterized by low imprisonment rates and humane prison conditions as approximate to life outside. It has been successful in having one of the lowest recidivism and incarceration rates in the world much to the envy of many countries. Hence notwithstanding the duality, Norways' treatment of drug users is in accordance with sustainable goals. The continued existence of penal exceptionalism, however does have its own share of national challenges as reiterated earlier. Singapore, in contrast has no intention of adopting the two step decriminalization or abolishing its punitive drug laws. Notwithstanding its comprehensive and structured rehabilitation program aimed at ensuring rehabilitation and reintegration is sustainably aligned and inclusive. Resources have not been spared in fostering an effective and sustainable rehabilitation. The practice of penal exceptionalism would as a precondition requires a strong welfare state with egalitarian values which would be a challenge to implement for countries absent these fundamentals. Having regard to the drug approaches of these countries, it can be argued that the classic binary categorization of drug approaches may not be the most appropriate manner to assess its alignment and compatibility to sustainable development goals. Perhaps the approach lies in evaluating the balance struck between the prohibitionists' and harm reduction fundamentals within each national drug policy to ascertain its compatibility and alignment to sustainable goals. Both Norway and Singapore, the former to a greater degree has embarked on comprehensive, inclusive and structured harm reduction services consistent with the sustainable goals.

Two other ancillaries pertinent to sustainable drug approaches must be considered. First, health outcomes as an important metric in assessing success and sustainability of drug approaches given its impact on the five dimensions of sustainable development. Second whether drug policy can be delinked from abstinence.

\section{Factoring Health Outcomes in the Balance Calculus}

Health outcomes are a useful criterion for measuring the success and sustainability of national drug policies. The Lancet Commission has opined that the pursuit of prohibitionist drug policies has worsened public health outcomes as 
there is a failure to take into account emerging scientific evidence on public health arising from drug control policies and abstinence-based approaches (The Lancet Commission, 2016). ${ }^{46}$

Prohibitionists drug policies and abstinence-based approaches are said to contribute to the spread of the human immunodeficiency virus ("HIV"), hepatitis C virus and tuberculosis linked to drug injections (“TB”). Countries with such policies and approaches generally do not provide for harm reduction services such as needle and syringe exchange programs, including other injection equipment; use of non-injected opioids; $\mathrm{OST}^{47}$ and other drug dependence treatment; HIV testing and counselling; antiretroviral therapy; condom programs for people who use drugs and their sexual partners; targeted information; education and communication for people who use drugs; etc. (The Lancet Commission, 2016). The 2014 Gap Report evidenced that the prevalence of HIV infection among people who inject drugs is notably much higher than that of the general population (UNAIDS, 2014). ${ }^{48}$ Though the global incidence of HIV has declined by 35\% from 2000 to 2014, new infections in Central Asia and Eastern Europe have increased by $30 \% .65 \%$ of the latter was due to due to unsafe drug injections (UNAIDS, 2015; The Lancet Commission, 2016). A marked increase in hepatitis $\mathrm{C}$ virus ("HCV") infection and higher risk of TB among people who inject drugs have also been observed (World Health Organization, 2016). Given the spread of HIV, HCV and TB among injecting drug users it has been recommended that harm reduction services be rendered to drug users (The Lancet Commission, 2016). European ${ }^{49}$ and American needle exchange programs and European funded programs for harm reduction and prevention measures are a direct response to an increase in HCV, HIV and/or TB infection incidence amongst drug users who inject. Additionally, in several European countries, there are medically supervised rooms for injection, smoke and inhalation of illicit drugs to prevent overdose fatalities and to provide clean equipment to drug users, amongst others (EMCDDA, 2015b; EMCDDA, 2018a). The European Union has also co-funded projects, such as "Improving Prison Conditions by Strengthening Infectious Disease Monitoring" which was implemented under the lead of the Harm Reduction International in 2015 and 2016, amongst others. These efforts in parts of Europe indicate clearly that the harm reduction efforts/services are premised on scientifically based findings to improve public health outcomes. For similar reasons, evidence-based treatment interventions for drug users were introduced in Singapore.

\footnotetext{
${ }^{46}$ The authors are of the view that prohibiting control drugs does contribute to lethal violence, spread of communicable diseases, discrimination, etc.

${ }^{47}$ However, Singapore does provide for OST and evidence-based treatment interventions in its drug rehabilitation programs for drug users/abusers as indicated above.

${ }^{48}$ The data reflected covers the period of five years from 2009 to 2014.22 countries were included in this study including Malaysia, Indonesia, Thailand, Myanmar, Moldova and Australia.

${ }^{49}$ Norway for instance started the "Needle Bus" way back in October 1988, which has been on the roads on a daily basis providing free clean needles and condoms to drug users to prevent the spread of communicable diseases. The bus is run jointly by the municipality of Oslo and the Norwegian Board of Health. See Skretting, 2002.
} 
Singapore does not practice a needle exchange program but does provide for OST and evidence-based treatment interventions for its drug users in its care. Studies have shown that OST treatment does reduce the incidence of HCV infection amongst drug users who inject. ${ }^{50}$ This is in line with the recommendation of the Lancet Commission which advocated proper prevention or treatment services for drug use and injection during imprisonment or detention.

The Lancet Commission has also recommended that drug markets be regulated so as to curb the formation of unregulated illegal markets resulting in adulterated drugs contributing to overdose fatalities and increased violence (The Lancet Commission, 2016). For instance, with respect to heroin assisted treatment ("HAT"), Switzerland and Germany have taken control of the procedure. By so doing, these countries are able to control the purity, and the dosage of controlled drugs amongst others to reduce overdose fatalities (Farrell \& Hall, 2015). Supervised injection sites in European countries ${ }^{51}$ have also contributed to reduced fatalities. The Lancet Commission has justified its basis for assisted drug dependence treatment programs by relying on studies which showed that the costs of crime reduction was significant in comparison to costs of drug dependence treatment, notwithstanding the numerous methodological challenges in evaluating and accounting costs associated with drug related crime, productivity losses, relapse data, etc. (The Lancet Commission, 2016).

One other point that is deserving of mention is that the Lancet Commission has recommended decriminalizing minor and non-violent drug offences to improve public health outcomes. By decriminalizing such offences, the costs savings of prison resources can be diverted to provide harm reduction treatment services to drug users. Decriminalization coupled with adequate harm reduction services has been argued to reduce incidence of HIV, HCV, TB infections generally for reasons stated above. Further, resources allocated for rehabilitation of such minor non-violent drug transgressions are expected to give the best returns (The Lancet Commission, 2016). Singapore adopts a similar logic in its rehabilitation of youth and low risk drug offenders, by keeping the former out of the DRC and providing counselling and structural and family support and for the latter, an enhanced treatment and rehabilitation program. ${ }^{52}$

Striking a balance in national drug policies between maintaining access to harm reduction services and retaining strong measures to prevent diversion and/or misuse of such drugs is a difficult task given jurisdictional nuances. Notwithstanding, it would appear that there is a valid justification for health, development and human rights indicators to be used in metrics to judge success and ${ }^{50}$ Studies from the United Stated of America, United Kingdom, Canada and Australia have shown that OST treatment has substantially reduced risk of HCV among drug users. See The Lancet Commission, 2016.

${ }^{51}$ Public supervised drug injection facilities were first opened in Norway in 2005. As of 2018, there are 78 official drug consumption facilities operating in seven EMCDDA reporting countries, including Norway, Netherlands, Germany, Denmark, Spain, France and Luxembourg. See EMCDDA, 2018 b.

${ }^{52}$ Refer to the Youth Enhanced Supervision Scheme for young low risk offenders as earlier discussed. 
sustainability of drug policies (The Lancet Commission, 2016). Though countries have not used these indicators in its entirety, countries, including Norway and Singapore have adopted a "mix and match" approach of these indicators to sustainably enhance the availability of harm reduction services to drug users.

\section{Delinking Drug Policy from Abstinence}

The Commission's sustainable approach does require a mindset change to drug use, control and prohibition amounting to de-linking of drug policy from abstinence. Embracing harm reduction drug policies generally in European countries and the softening of harm eradication policies coupled with the increased provision of harm reduction services in the some of the Southeast Asian countries is a reflection of that mindset change. However, can that mindset change evolve to delinking drug policy from abstinence? It is contended that it is only a matter of time before that Rubicon is crossed.

Law is not static and neither are our mindsets. Being shackled to our past is not an option. With the advent of globalization, changing attitudes to drugs, scientific developments in using certain controlled drugs for medicinal purposes, medical developments on theories of drug use and with the growth of the millennium generation, it may only be a matter of time before drug policies are delinked from abstinence.

In Singapore, for instance there are already signs of the younger generation breaking away from current mindsets and attitudes to drugs and drug use. Key drug statistics provided by CNB for 2018, shows that drug use is on the rise among the young. The number of drug abusers/users for 2018 has increased by $11 \%$ from the previous year (Central Narcotics Bureau, 2019a; More new drug abusers arrested in 2018, most under 30: CNB, 2019). ${ }^{53}$ However, $40 \%$ of the total number of drug users for 2018, were first time abusers/users. Of that it is interesting to note that $64 \%$ of the first-time abusers in this category are individuals under the age of $30 .^{54}$

Additionally, over the last year or so, the debate to legalize medical cannabis has taken flight in Southeast Asia. Thailand legalized medical cannabis last year, the first in Southeast Asia (Paulo \& Woo, 2019), and this is even though the country has always waged a tough war on controlled drugs. The legalization arguably does not signal a turning point in this war, as it only covers cannabis used for medical purposes, grown under tight regulations by authorities. ${ }^{55}$ All other

\footnotetext{
${ }^{53} 3,438$ drug abusers were arrested in 2018, an increase from 3,091 drug abusers in 2017. There was also an increase in the number of repeat drug abusers from 1,842 in 2,017 to 2072 in 2018, noting a $12 \%$ increase. Given the rampant drug addiction issues, this is not a surprising fact.

${ }^{54} 75 \%$ of these individuals below 30 are reported to be abusing methamphetamines. The CNB did attribute the increase to abuse of synthetic drugs, methamphetamine and psychoactive substances. Methamphetamines also accounted for $75 \%$ amongst the new drug abusers. See Central Narcotics Bureau, 2019a; More new drug abusers arrested in 2018, most under 30: CNB, 2019. Likewise, a similar increase in abuse of synthetic drugs has been noted in the European market. See EMCDDA, 2018 a.

${ }^{55}$ This is opposed to cannabis being used for recreation. Besides, legalizing cannabis for medicinal purposes does open a legal market amounting to billions of dollars.
} 
controlled drugs remain illegal and strict enforcement and punitive laws to this end remain business as usual. Furthermore, Malaysia and the Philippines are also considering mirroring the approach taken by Thailand. Following this legalization by Thailand, polls were taken by Singaporean Ministry of Home Affairs ("MHA") to understand the views of sample Singaporeans. It was reported that $87.1 \%$ were of the view that cannabis abuse should remain illegal. However, those aged 13 to 30 showed a lower level of support (79.9\%) compared to those who were older (89.2\%). Accordingly, the MHA concluded that the younger respondents generally hold a more liberal view of drugs and in particular cannabis (Kwang, 2019).

The CNB's outreach efforts on preventative education on drugs, to raise awareness on the harmful effects of drugs amongst youth and establish a network of youth anti-drug advocates, coupled with the government's affirmation on punitive drug laws and a deterrent sentencing regime imposed by the courts for drug offenders, continue to remain a focal point. However, to what extent that would change the younger generation's liberal views on drugs and its uses remains to be seen.

Similar liberal view and use of drugs amongst younger respondents is also noted in Europe and the United Kingdom. In the 2018 European Drug Report ("EDR"), the data collated suggested that "drug availability is high and in some areas even increasing" presenting new challenges to existing national and European responses to drug use and drug-related problems (EMCDDA, 2018a). ${ }^{56}$ Cannabis remains the most widely used illicit drug in Europe (EMCDDA, 2018a). ${ }^{57}$ In 2017, cannabis ${ }^{58}$ was abused by 24 million individuals between the ages of 15 and 64 of which 17.2 million were from ages 15 to 34, with France having the highest rates of abuse (EMCDDA, 2018a). It was noted in the EDR that drug use was concentrated amongst young adults and an estimated 18.9 million young adults (aged between 15 and 34) used drugs in the year before the report (EMCDDA, 2018a). The preponderance of drug use amongst young adults in Europe would suggest that likewise, younger respondents generally may have a more liberal view of drugs and its use, in particular cannabis.

${ }^{56}$ See also EMCDDA, 2019 which reported an increase in cocaine residues in waste water analysis of European Cities from 2011 to 2018. This project analyzed wastewater in around 70 European cities and towns to explore the drug consuming patterns, including the quantity of drugs consumed by those who live in them. The results provided a valuable snapshot of the drug flow through the concerned cities. Wastewater analysis is a useful complement to establishing monitoring tools in drugs area. It is not subject to response and nonresponse bias and can better identify the true spectrum of drugs being consumed, as drug users are often unaware of the actual mix of substances they take. This tool also has the potential to provide information in short timeframes on geographical and temporal trends.

${ }^{57}$ See also EMCDDA, 2019. No results for cannabis use was reported in the updated waste water analysis as cannabis use is estimated by measuring its main metabolite (THC-COOH), which is the only suitable biomarker found so far, but is excreted in a low percentage. It was stated that more research is needed to understand the excretion percentage of $\mathrm{THC}-\mathrm{COOH}$ or find alternative biomarkers. See Causanilles et al., 2017.

${ }^{58}$ Cannabis products accounted for largest share (38\%) of the European Union illegal drug retail market. See EMCDDA, 2018a. 
To add to this dimension, the science behind drug use and dependence is as varied as the drugs themselves (Lettieri, Sayers, \& Pearson, 1980). First, ranging from the theory of simple addiction to auto-medication to alleviate stressful states of being, the proponents of some these theories contend that the current drug treatment plans and programs are simply unsuitable as it does not truly deal with the cause of drug abuse/use (Lettieri, Sayers, \& Pearson, 1980). This proposition corroborates the Lancet Commission's concern that drug policies "are often colored by ideas about drugs use and dependence that are not scientifically grounded" (The Lancet Commission, 2016). Second, some proponents in the medical field are of the view that prohibition of production, supply and use of certain drugs has created negative externalities such as adulterated drugs in the illegal markets, overdose fatalities, spread of HIV and hepatitis B and C infection among injecting drug users, etc. (Rolles, 2010). Given the myriad of drug use and dependence theories ${ }^{59}$ as well as negative externalities, could de-linking drug policy from abstinence be the unifying catalyst in crossing the rubicon?

The paradigm first shifted when harm reduction methods were embraced and/or harm reduction services were increased. Some European countries and Norway have pushed this further by delinking drug policy from abstinence. This perhaps will be the eventuality even for countries adamant not to do so given the coming together of various important factors mentioned above. Drawing from the above, it appears at a generic level four factors are crucial for delinking drug policy from abstinence: people, drugs, science and sustainability. The younger generation will move towards delinking as they have a different attitude towards drugs and its uses. Even preventative education on drugs, punitive laws and deterrent sentencing in some countries has neither deterred the increase in drug use nor use amongst first timers. Singapore is no exception as demonstrated by its statistics on increase of drug abusers and first time drug abusers. It must be remembered that countries with an aging population, like Singapore, will face the mindsets of the younger generation when they come to form the majority of the population. Increasing drug use with a good percentage of first time users has brought about increasing negative externalities ${ }^{60}$ and challenges that needs to be reckoned sustainably. This reckoning will confront the need to delink drug policy from abstinence. Advancement in science behind drug use and dependence, providing more effective evidence based treatment measures, and acknowledging effective medicinal use of certain drugs will not only set the foundation to make delinking possible but probable. It may well become the unifying ${ }^{59}$ Necessitating corollary drug treatment options.

${ }^{60}$ This refers to negative externalities caused by prohibitionist and abstinence centric drug policies. An externality is the cost or benefit that affects a party who did not choose to incur that cost or benefit. A negative externality is an economic activity that imposes a negative effect on an unrelated third party. See Buchanan \& Stubblebine, 2006. Negative externalities include exacerbated public health problems, increased incarceration rates, under-treatment of chronic pain, corruption, compounding harm to users, decreasing quality of drugs made resulting in accidental overdoses or poisoning of drug users etc. See Friedman, 1998; Miron \& Zwiebel, 1995; and Kuziemko \& Levitt, 2004. 
catalyst in this trend. Adding to this dimension draining resources and government coffers may trigger the move in favor of treating drug dependence per se and de-linking drug policy from abstinence like in other behavior related policies. ${ }^{61}$ Perhaps, this may then pave the way for regulated legalization.

\section{Conclusion}

Tackling drug problem nationally in accordance with sustainable development goals is a constant work in progress within national nuances. The Commission's sustainable development goals are not a tall order. It is practical and achievable. The European model, including the approach taken by the Nordic countries has routed its drug approach more or less in accordance with this order. Norway's model is said to encompass penal exceptionalism, however, there are challenges to its continued existence. Legalization of drugs for medicinal purposes and provision of extensive harm reduction services reduces the demand in the illegal drug market and accordingly negative externalities.

For other countries, it is a constant work in progress as the right balance has to be struck between the Commission's goals and national drug issues. For most, if not all countries, the drug trafficker will always be viewed as a criminal to be subjected to maximum penal punishment notwithstanding the decriminalization of drug consumption and possession and to a limited extent cultivation. However, the drug dependent is now being viewed as "ill" requiring treatment as it concerns a public health issue, and this is even amongst countries that punish traffickers and dealers punitively. For a start, if we were to divorce the drug policies relating to the drug trafficker and the drug dependent, it would appear that the policies relating to the latter in some countries such as Singapore ticks most of the sustainable goal boxes. On the other hand, the practice of penal exceptionalism requires a strong welfare state and egalitarian values which would be a challenge to apply in countries that absent these fundamentals.

Some of the drug models do take into account health, development and human rights indicators as metrics to judge success of their drug policies since these outcomes impact all five dimensions of sustainable development. Most countries have not used these indicators in its entirety, but countries have adopted a "mix and match" approach of these indices to sustainably enhance harm reduction services to drug users. It remains to be seen whether increasing negative externalities may persuade prohibitionists and abstinence-based drug policy advocates to consider such metrics to judge the success of their model.

The Commission's sustainable approach requires fundamentally a change in mindset to drug use, control and prohibition. The paradigm has shifted for those using the European model. The other countries which have started increasing their harm reduction services and softening their harm eradication policies are demonstrating receptiveness to the changing dynamics of drug control. However, for prohibitionists and abstinence-based advocates, de-linking drug policy

${ }^{61}$ As in the case concerning liquor or cigarette consumption. 
from abstinence still remains a difficult issue. Globalization, negative externalities, liberal attitudes of the young towards drugs, allowing use of controlled drugs for medicinal purposes, understanding the science behind drug use and drug dependence and basing drug policies on scientific grounds may tilt the balance in favor of treating drug dependence per see and de-linking drug policy from abstinence like in other behavior-related policies.

\section{Conflicts of Interest}

The author declares no conflicts of interest regarding the publication of this paper.

\section{References}

(1972). United Nations Single Convention on Narcotic Drugs of 1961 as Amended by the 1972 Protocol, 976 U.N.T.S. 14152.

(2014). New Govt-Run Halfway House for Ex-Offenders to Be Ready by 2018. Today Online.

https://www.todayonline.com/singapore/new-govt-run-halfway-house-ex-offenders-be -ready-2018

(2019). Adili Chibuike Ejike v. Public Prosecutor, SGCA 38 (Sing.).

(2019). More New Drug Abusers Arrested in 2018, Most under 30: CNB. Channel News Asia.

https://www.channelnewsasia.com/news/singapore/more-new-drug-abusers-arrested-2 018-most-under-30-cnb-11286574

(2019). Singapore Parliamentary Report (Vol. 94).

Ang, D. (2019). Three Things You Should Know about the Enhanced Drug Rehabilitation Regime. Singapore: Ministry of Home Affairs.

https://www.mha.gov.sg/hometeamnews/on-assignment/ViewArticle/three-things-you -should-know-about-the-enhanced-drug-rehabilitation-regime

Buchanan, J. M., \& Stubblebine, C. W. M. (2006). Externality. In Inframarginal Contributions to Development Economics (pp. 55-73). Singapore: World Scientific Publishing. https://doi.org/10.1142/9789812774255 0004

Causanilles, A., Baz-Lomba, J. A., Burgard, D. A., Emke, E., González-Mariño, I., Krizman-Matasic, I., Bijlsma, L. et al. (2017). Improving Wastewater-Based Epidemiology to Estimate Cannabis Use: Focus on the Initial Aspects of the Analytical Procedure. Analytica Chimica Acta, 988, 27-33. https://doi.org/10.1016/j.aca.2017.08.011

Central Narcotics Bureau (2019a). Drug Situation Report 2018. https://www-cnb-gov-sg-admin.cwp.sg/docs/default-source/drug-situation-report-doc uments/cnb-annual-statistics- 2018.pdf

Central Narcotics Bureau (2019b). Misuse of Drugs Act (MDA). https://www.cnb.gov.sg/NewsAndEvents/News/Index/misuse-of-drugs-act-(mda)

Crewe, B., \& Liebling, A. (2012). Are Liberal-Humanitarian Penal Values and Practices Exceptional? In T. Ugelvik, \& J. Dullum (Eds.), Penal Exceptionalism? Nordic Prison Policy and Practice (pp. 175-198). New York: Routledge.

Data.gov.sg. (n.d.-a). Inmates Admitted to Undergo Treatment and Rehabilitation in Drug Rehabilitation Centre (DRC).

https://data.gov.sg/dataset/inmates-admitted-to-undergo-treatment-and-rehabilitation 
-in-drug-rehabilitation-centre-drc

Data.gov.sg. (n.d.-b). Inmates Released from Drug Rehabilitation Centre (DRC). https://data.gov.sg/dataset/inmates-released-from-drc

European Monitoring Centre for Drugs and Drug Addiction (EMCDDA) (2015a). Alternatives to Punishment for Drug-Using Offenders. http://www.emcdda.europa.eu/system/files/publications/1020/TDAU14007ENN.pdf

European Monitoring Centre for Drugs and Drug Addiction (EMCDDA) (2015b). European Drug Report 2015. http://www.emcdda.europa.eu/edr2015

European Monitoring Centre for Drugs and Drug Addiction (EMCDDA) (2017). Cannabis Legislation in Europe: An Overview. http://www.emcdda.europa.eu/system/files/publications/4135/TD0217210ENN.pdf

European Monitoring Centre for Drugs and Drug Addiction (EMCDDA) (2018a). European Drug Report 2018. http://www.emcdda.europa.eu/edr2018

European Monitoring Centre for Drugs and Drug Addiction (EMCDDA) (2018b). Drug Consumption Rooms: An Overview of Provision and Evidence. http://www.emcdda.europa.eu/system/files/publications/2734/POD Drug\%20consump tion\%20rooms.pdf

European Monitoring Centre for Drugs and Drug Addiction (EMCDDA) (2018c). Norway Drug Report 2018.

http://www.emcdda.europa.eu/system/files/publications/11315/norway-cdr-2018-withnumbers.pdf

European Monitoring Centre for Drugs and Drug Addiction (EMCDDA) (2019). Wastewater Analysis and Drugs: A European Multi-City Study.

http://www.emcdda.europa.eu/system/files/publications/2757/POD Wastewater\%20an alysis update2019.pdf

European Monitoring Centre for Drugs and Drug Addiction (EMCDDA), \& Europol. (2009). Methamphetamine: A European Union Perspective in the Global Context.

https://www.europol.europa.eu/sites/default/files/documents/emcdda-europol-metham phetamine.pdf

Farrell, M., \& Hall, W. (2015). Heroin-Assisted Treatment: Has a Controversial Treatment Come of Age? The British Journal of Psychiatry: The Journal of Mental Science, 207, 3-4. https://doi.org/10.1192/bjp.bp.114.160986

Foucault, M. (1995). Discipline and Punish: The Birth of the Prison. New York: Vintage Books.

Friedman, M. (1998). There's No Justice in the War on Drugs. New York Times. https://miltonfriedman.hoover.org/friedman images/Collections/2016c21/NYT 0111 1998.pdf

Gesetz über den Verkehr mit Betäubungsmitteln (Betäubungsmittelgesetz-BtMG) [Narcotics Act], as Amended (Ger.).

https://www.gesetze-im-internet.de/btmg_1981/BtMG.pdf

Global Commission on Drug Policy (2011). War on Drugs: Report of the Global Commission on Drug Policy.

https://www.globalcommissionondrugs.org/wp-content/themes/gcdp v1/pdf/Global C ommission Report English.pdf

Global Commission on Drug Policy (2016). Advancing Drug Policy Reform: A New Approach to Decriminalization.

http://www.globalcommissionondrugs.org/wp-content/uploads/2016/11/GCDP-Report 


\section{-2016-ENGLISH.pdf}

Hauge, R. (2009). Debating Decriminalization of Drug Use in Norway. Nordic Studies on Alcohol and Drugs, 26, 427-431. https://doi.org/10.1177/145507250902600407

Helse-og omsorgsdepartement (2012). Se meg! En helhetlig rusmiddelpolitikk: Alkohol-narkotika-doping [See Me! A Holistic Drug Policy: Alcohol-Drugs-Doping]. https://www.regjeringen.no/contentassets/bba17f176efc40269984ef0de3dc48e5/no/pdfs /stm201120120030000dddpdfs.pdf

Husabø, E. J. (2013). Counterterrorism and the Expansion of Proactive Police Powers in the Nordic States. Journal of Scandinavian Studies in Criminology and Crime Prevention, 14, 3-23. https://doi.org/10.1080/14043858.2013.773759

Jalelah, A. B. (2013). Pre-Release Rehab for High-Risk Drug Offenders. The Straits Times.

http://www.asiaone.com/print/News/Latest\%2BNews/Singapore/Story/A1Story201304 03-413319.html

Jewkes, Y., \& Gooch, K. (2019). How Lessons in Scandinavian Design Could Help Prisons with Rehabilitation. The Conversation.

http://theconversation.com/how-lessons-in-scandinavian-design-could-help-prisons-w ith-rehabilitation-106554

Jilani, Z. (2011). As the Right Bemoans Norway's Criminal Justice System, It Is One of the Safest Countries on Earth. ThinkProgress.

https://thinkprogress.org/as-the-right-bemoans-norways-criminal-justice-system-it-isone-of-the-safest-countries-on-earth-f181a7585493

John Hopkins-Lancet Commission on Drug Policy and Health (The Lancet Commission) (2016). Public Health and International Drug Policy. The Lancet, 387, 1427-1480. https://doi.org/10.1016/S0140-6736(16)30115-5

Joint United Nations Programme on HIV/AIDS (UNAIDS) (2014). The Gap Report. http://files.unaids.org/en/media/unaids/contentassets/documents/unaidspublication/20 14/UNAIDS Gap report en.pdf

Joint United Nations Programme on HIV/AIDS (UNAIDS) (2015). How AIDS Changed Everything-MDG6: 15 Years, 15 Lessons of Hope from the AIDS Response. https://www.unaids.org/en/resources/documents/2015/MDG6 15years-15lessonsfromt $\underline{\text { heAIDSresponse }}$

Justis-og politidepartement (2008). About the Act on Amendments to the Penal Code of 20 May 2005 No. 28 (Last Sub-Proposal-Finalization of Special Part and Adaptation of Other Legislation.

Khalip, A. (2015). EU Drug Agency Sees No U.S-Like Cannabis Legalization Moves. Reuters. https://www.reuters.com/article/us-drugs-europe-idUSKBN0OK1U220150604

Koman, R. N. (2018). It Is Not about the Drugs: A Comparative and Contextual Analysis of Singapore and European Approach to Drug Issues. Beijing Law Review, 9, 439-459. https://doi.org/10.4236/blr.2018.93027

Krimināllikums [Criminal Law] 17.5.1998 Likums/LV, 199/200 (1260/1261) (Lat.).

Kriminalomsorgen (n.d.). About the Norwegian Correctional Service. http://www.kriminalomsorgen.no/index.php?cat=265199

Kuziemko, I., \& Levitt, S. D. (2004). An Empirical Analysis of Imprisoning Drug Offenders. Journal of Public Economics, 88, 2043-2066. https://doi.org/10.1016/S0047-2727(03)00020-3

Kwang, K. (2019). Younger Singaporeans' Support for Capital Punishment for Drug Traf- 
fickers below National Average: MHA Survey. Channel News Asia. https://www.channelnewsasia.com/news/singapore/younger-singaporeans-support-cap ital-punishment-drug-traffickers-11542036

Leafly (n.d.). Home Cannabis Cultivation Laws: A State-by-State Guide. https://www.leafly.com/news/cannabis-101/home-cannabis-cultivation-laws-a-state-by -state-guide

Lettieri, D. J., Sayers, M., \& Pearson, H. W. (1980). Theories on Drug Abuse: Selected Contemporary Perspectives. Rockville, MD: National Institute on Drug Abuse.

Lov om legemidler $m v$ [Act Relating to Medicinal Products] 4. Desember 1992 nr. 132 (Nor.). Lov om ordning med lokaler for injeksjon av narkotika (sprøyteromsloven) [Law on Scheme of Premises for Drug Injection (Drug Injection Rooms Act)] 2. juli 2004 nr. 64 (Nor.).

Lov om straff (straffeloven) [Penal Code] 20. mai 2005 nr. 28 (Nor.).

Mathiesen, T. (2012). Scandinavian Exceptionalism in Penal Matters: Reality or Wishful Thinking? In T. Ugelvik, \& J. Dullum (Eds.), Penal Exceptionalism? Nordic Prison Policy and Practice (pp. 13-37). New York: Routledge.

Ministry of Home Affairs (2016). Keeping Singapore Drug-Free. https://www.mha.gov.sg/newsroom/others/news/keeping-singapore-drug-free

Ministry of Home Affairs (2019). Commencement of the Misuse of Drugs (Amendment) Act 2019. https://www.mha.gov.sg/newsroom/press-release/news/commencement-of-the-misuse -of-drugs-amendment-act-2019

Miron, J. A., \& Zwiebel, J. (1995). The Economic Case Against Drug Prohibition. Journal of Economic Perspectives, 9, 175-192. https://doi.org/10.1257/jep.9.4.175

Misuse of Drugs (Amendment) Act 2019, Act 1 of 2019 (Sing.).

Misuse of Drugs Act (MDA), Rev. Ed. Cap 185 (2008) (Sing.).

Mitchell, O., Wilson, D. B., Eggers, A., \& MacKenzie, D. L. (2012). Assessing the Effectiveness of Drug Courts on Recidivism: A Meta-Analytic Review of Traditional and Non-Traditional Drug Courts. Journal of Criminal Justice, 40, 60-71. https://doi.org/10.1016/j.jcrimjus.2011.11.009

Mjåland, K., \& Lundeberg, I. (2014). Penal Hybridization: Staff-Prisoner Relationships in a Norwegian Drug Rehabilitation Unit. In H. S. Aasen, S. Gloppen, A. M. Magnussen, \& E. Nilssen (Eds.), Juridification and Social Citizenship in the Welfare State (pp. 183-202). Cheltenham, Northampton, MA: Edward Elgar Publishing. https://doi.org/10.4337/9781783470235.00015

Paulo, D. A., \& Woo, G. (2019). Promising or Harmful? A Debate Ensues after Thailand Legalises Medical Cannabis. Channel News Asia. http://www.channelnewsasia.com/news/singapore/promising-harmful-debate-thailand -legalises-medical-cannabis-11240976? cid=h3 referral inarticlelinks 24082018 cna

Phys.org (2018). Rivers Worldwide Threatened by Pharma Waste: Studies. https://phys.org/news/2018-04-rivers-worldwide-threatened-pharma.html

Pratt, J. (2008a). Scandinavian Exceptionalism in an Era of Penal Excess, Part I: The Nature and Roots of Scandinavian Exceptionalism. The British Journal of Criminology, 48, 119-137. https://doi.org/10.1093/bjc/azm072

Pratt, J. (2008b). Scandinavian Exceptionalism in an Era of Penal Excess, Part II: Does Scandinavian Exceptionalism Have a Future? The British Journal of Criminology, 48, 275-292. https://doi.org/10.1093/bjc/azm073 
Reglamento Penitenciario (R.D. 1996, 190) (Spain).

Rolles, S. (2010). An Alternative to the War on Drugs. British Medical Journal, 341, 127-128. https://doi.org/10.1136/bmj.c3360

Shammas, V. L. (2014). The Pains of Freedom: Assessing the Ambiguity of Scandinavian Penal Exceptionalism on Norway's Prison Island. Punishment \& Society, 16, 104-123. https://doi.org/10.1177/1462474513504799

Shammas, V. L. (2016). The Rise of a More Punitive State: On the Attenuation of Norwegian Penal Exceptionalism in an Era of Welfare State Transformation. Critical Criminology, 24, 57-74. https://doi.org/10.1007/s10612-015-9296-1

Singapore Corporation of Rehabilitative Enterprises (n.d.). Halfway Houses. https://www.score.gov.sg/programmes-services/community-partnerships/halfway-hous $\underline{\text { es }}$

Skretting, A. (2002). Public Injection Rooms, a Help to Heroin Addicts? Nordic Studies on Alcohol and Drugs, 19, 33-49. https://doi.org/10.1177/145861260201901S11

Skretting, A. (2014). Governmental Conceptions of the Drug Problem: A Review of Norwegian Government Papers 1965-2012. Nordic Studies on Alcohol and Drugs, 31, 569-584. https://doi.org/10.2478/nsad-2014-0047

Sterbenz, C. (2014). Why Norway's Prison System Is So Successful. Business Insider. https://www.businessinsider.com/why-norways-prison-system-is-so-successful-2014-1 $\underline{2 / ? \mathrm{IR}=\mathrm{T}}$

Stevenson, B. (2011). Drug Policy, Criminal Justice and Mass Imprisonment. Global Commission on Drug Policies.

http://www.globalcommissionondrugs.org/wp-content/themes/gcdp v1/pdf/Global C om Bryan Stevenson.pdf

Stoltenbergutvalget (2010). Report on Drugs.

https://www.regjeringen.no/globalassets/upload/hod/rappomnarkotika nettversjon.pdf

Suchtmittelgesetz [smg] [Addictives Law] bundesgesetzblatt [bgbl] No. 112/1997, as Amended (Austria).

https://www.ris.bka.gv.at/GeltendeFassung.wxe?Abfrage=Bundesnormen\&Gesetzesnu $\underline{\text { mmer }=10011040}$

Trestní zákon [Criminal Code] Zákon č 40/2009 Sb. (Czech).

Ugelvik, T. (2013). Seeing like a Welfare State: Immigration Control, Statecraft, and a Prison with Double Vision. In K. F. Aas, \& M. Bosworth (Eds.), The Borders of Punishment: Migration, Citizenship, and Social Exclusion (pp. 183-200). Oxford: Oxford University Press. https://doi.org/10.1093/acprof:oso/9780199669394.003.0011

United Nations General Assembly (2015). Transforming Our World: The 2030 Agenda for Sustainable Development. Resolution 70/1.

United Nations High Commissioner for Human Rights (2015). Study on the Impact of the World Drug Problem on the Enjoyment of Human Rights.

https://www.ohchr.org/EN/HRBodies/HRC/RegularSessions/Session30/Documents/A HRC $30 \quad 65$ AEV.docx

United Nations Office on Drugs and Crime (UNODC) (2008). Drug-Free ASEAN 2015: Status and Recommendations.

https://www.unodc.org/documents/southeastasiaandpacific/Publications/ASEAN 2015 .pdf

United Nations Office on Drugs and Crime (UNODC) (2016). World Drug Report 2016. https://www.unodc.org/doc/wdr2016/WORLD DRUG REPORT 2016 web.pdf 
World Health Organization (2016). Guidelines for the Screening, Care and Treatment of Persons with Chronic Hepatitis C infection.

https://www.who.int/hepatitis/publications/hepatitis-c-guidelines-2016/en

World Prison Brief (n.d.). World Prison Brief Data: Norway.

http://www.prisonstudies.org/country/norway

Yew, L. (1999). Effective Treatment Measures for Prisoners and Drug Addicts to Facilitate Their Reintegration into Society (pp. 301-314). UNAFEI Resource Material Series No. 54. 